\title{
A comparison between elemental and compound training of cues in retrospective revaluation
}

\author{
MARTHA ESCOBAR, OSKAR PINEÑO, and HELENA MATUTE \\ Universidad de Deusto, Bilbao, Spain
}

\begin{abstract}
Associative learning theories assume that cue interaction and, specifically, retrospective revaluation occur only when the target cue is previously trained in compound with the to-be-revalued cue. However, there are recent demonstrations of retrospective revaluation in the absence of compound training (e.g., Matute \& Pineño, 1998a, 1998b). Nevertheless, it seems reasonable to assume that cue interaction should be stronger when the cues are trained together than when they are trained apart. In two experiments with humans, we directly compared compound and elemental training of cues. The results showed that retrospective revaluation in the elemental condition can be as strong as and, sometimes, stronger than that in the compound condition. This suggests that within-compound associations are not necessary for retrospective revaluation to occur and that these effects can possibly be best understood in the framework of general interference theory.
\end{abstract}

In the literature of animal conditioning and human associative learning, it is well known that if a cue, $\mathrm{X}$, is consistently followed by an outcome, $\mathrm{O}$ (i.e., $\mathrm{X}-\mathrm{O}$ ), $\mathrm{X}$ is generally learned as a predictor of the occurrence of the outcome. It is also well known that responding to $\mathrm{X}$ in a subsequent test phase becomes altered if another cue, $\mathrm{A}$, is trained in compound with $\mathrm{X}$ as a predictor of the same outcome. Some classic instances of these cue interaction effects in the animal learning literature are overshadowing (Pavlov, 1927), blocking (Kamin, 1968), conditioned inhibition (Pavlov, 1927), and the relative stimulus validity effect (Wagner, Logan, Haberlandt, \& Price, 1968). These effects have also been demonstrated with human participants (e.g., Chapman, 1991; Matute, Arcediano, \& Miller, 1996; Shanks, López, Darby, \& Dickinson, 1996; Wasserman, Kao, Van Hamme, Katagari, \& Young, 1996). They are important because they suggest that in situations in which there are two potential predictors of the same outcome, humans and other animals tend to selectively respond to one of those predictors, with the other one generally being behaviorally disregarded as a reliable predictor of the outcome.

Despite the great relevance of cue interaction effects to our understanding of the principles of learning, the

Support for this research was provided by Grant PI-2000-12 from the Departamento de Educación, Universidades e Investigación of the Basque Government to H.M. O.P. was supported by a F.P.I. fellowship from the Spanish Ministry of Education (Ref. AP98, 44970323). M.E. was supported by a Dissertation Year Fellowship granted by Binghamton University. We thank Leyre Castro and Mirko Gerolin for assistance in data collection and Francisco Arcediano, Leyre Castro, Nuria Ortega, and Sonia Vegas for comments on an earlier version of this manuscript. We also thank Jan De Houwer, Ralph Miller, and two anonymous reviewers for their insightful comments on the manuscript. M.E. is now at Binghamton University. Correspondence concerning this article should be addressed to H. Matute, Departamento de Psicología, Universidad de Deusto, Apartado 1, 48080 Bilbao, Spain (e-mail: matute@orion.deusto.es). mechanisms underlying these effects are not yet entirely clear. For example, there is disagreement concerning whether cue interaction takes place at the moment of acquisition (e.g., Rescorla \& Wagner, 1972) or at the moment of retrieval (e.g., Miller \& Matzel, 1988). Of more relevance for our present purposes, there is disagreement concerning whether compound training of the two cues is necessary for cue interaction to take place. In the present research, we look at the latter question, by comparing cue interaction effects that take place after compound or elemental training of two cues. (Importantly, the results of the present experiments also speak to the former question; however, it is not the purpose of this research to discriminate between acquisition and retrieval theories of cue interaction.)

Associative theories of acquisition (e.g., Rescorla \& Wagner, 1972; Wagner, 1981) and retrieval (e.g., Miller \& Matzel, 1988) assume that compound training is necessary for the occurrence of cue interaction. That is, if $X$ and $\mathrm{A}$ are never trained in compound, the expectation of the outcome when $\mathrm{X}$ is presented should be a result only of the previous $\mathrm{X}-\mathrm{O}$ pairings, regardless of whether or not A was trained as a predictor of the same outcome. Similarly, recent modifications of the Rescorla-Wagner model (e.g., Van Hamme \& Wasserman, 1994) and of Wagner's (1981) SOP model (e.g., Dickinson \& Burke, 1996) suggest that the occurrence of cue interaction and retrospective revaluation (a special type of cue interaction that could not be explained by their predecessor theories) depends on the cues' having acquired a withincompound association prior to the revaluation treatment.

Retrospective revaluation is a particularly interesting type of cue interaction because, contrary to other cue interaction effects, it reflects changes in responding to a cue $(\mathrm{X})$ without further presentations (training) of that cue. Rather, these changes in responding are brought 
about by training of an associate of X (e.g., Cue A) during Phase 2 with which $X$ was previously trained in compound (Phase 1). Instances of retrospective revaluation are backward blocking (e.g., Denniston, Miller, \& Matute, 1996; Miller \& Matute, 1996; Shanks, 1985; Wasserman \& Berglan, 1998), recovery from overshadowing (e.g., Kaufman \& Bolles, 1981; Larkin, Aitken, \& Dickinson, 1998; Matzel, Schachtman, \& Miller, 1985; Wasserman et al., 1996), and backward conditioned inhibition (Chapman, 1991; Larkin et al., 1998). As with other cue interaction effects, retrospective revaluation effects have also been interpreted as either retrieval or acquisition effects. The retrieval view posits that when cue $\mathrm{X}$ is presented at test, its associative strength is compared with that of A, and if A's strength has been modified during Phase 2, this will be reflected during testing as a change in responding to X (e.g., Miller \& Matzel, 1988). In contrast, the acquisition view posits that the associative strength of $\mathrm{X}$ is modified during each of the trials in which $\mathrm{A}$ is trained during Phase 2 , even though $\mathrm{X}$ is absent during those trials (e.g., Dickinson \& Burke, 1996; Van Hamme \& Wasserman, 1994).

It is with respect to retrospective revaluation effects that the greatest controversy exists concerning the necessity of compound training of the two cues. Although some studies suggest that compound training of cues is a necessary condition for retrospective revaluation to occur, others have presented evidence of retrospective revaluation in the absence of compound training. For example, there are several reports suggesting that retrospective revaluation can occur only when a within-compound association between $\mathrm{A}$ and $\mathrm{X}$ is acquired during the first phase of the study (e.g., Aitken, Larkin, \& Dickinson, 2001; Dickinson \& Burke, 1996; Wasserman \& Berglan, 1998). In contrast, Matute and Pineño (1998a, 1998b; see Escobar, Matute, \& Miller, 2001, for a nonhuman analogue) reported that human participants that received $\mathrm{X}-\mathrm{O}$ training followed by $\mathrm{A}-\mathrm{O}$ training showed impaired responding to $\mathrm{X}$ in a subsequent test phase, relative to a group that did not receive the $\mathrm{A}-\mathrm{O}$ training. Although this observation is contrary to the predictions of current theories of associative learning, it suggests that the learning of a new cue-outcome association during the second phase of training (i.e., A-O) can affect the expression of the previously acquired $\mathrm{X}-\mathrm{O}$ association, even though $X$ and $A$ had never received compound training. The decrease in responding to $X$ was due neither to the interval elapsed between training and testing with $\mathrm{X}$ nor to memory overload. Responding to $\mathrm{X}$ was unaffected if (1) the second phase consisted of A-no-O trials or mere exposure to the experimental context, with no cues or outcomes being presented (Matute \& Pineño, 1998b, Experiments 1 and 2), (2) the test of X was conducted in a context different from that in which $\mathrm{A}$ was trained (i.e., renewal effect; Matute \& Pineño, 1998b, Experiment 3), (3) the training trials for $\mathrm{A}$ and $\mathrm{X}$ were interspersed within a single phase, rather than conducted sequentially (Pineño, Ortega, \& Matute, 2000, Experi- ment 2), (4) a retention interval was introduced between training of $\mathrm{A}$ and testing on $\mathrm{X}$ (i.e., spontaneous recovery; Pineño et al., 2000, Experiment 1), or (5) either retrieval cues for the $\mathrm{X}-\mathrm{O}$ association or novel cues were presented immediately before testing (Pineño et al., 2000, Experiment 3).

Interaction between the $\mathrm{X}-\mathrm{O}$ and the $\mathrm{A}-\mathrm{O}$ associations seems to occur during retrieval, rather than during acquisition, because spontaneous recovery of the $\mathrm{X}-\mathrm{O}$ association is observed (Pineño et al., 2000, Experiment 1). Moreover, such interaction seems to occur maximally when the two cues have been associated to the same outcome and the interfering association $(\mathrm{A}-\mathrm{O})$ is of higher availability than the target association $(\mathrm{X}-\mathrm{O})$ at the time (or in the context) of testing. Therefore, in addition to within-compound associations, there seem to be other factors (e.g., recency and contextual manipulations) that determine whether the $\mathrm{A}-\mathrm{O}$ association will interfere with retrieval of the $\mathrm{X}-\mathrm{O}$ association at testing, thereby enhancing the $\mathrm{A}-\mathrm{O}$ association's potential to alter responding to the target cue during testing (see also Escobar, Arcediano, \& Miller, 2001; Escobar, Matute, \& Miller, 2001 , for analogue findings with nonhuman subjects).

Other data in the literature can also be interpreted as evidence of interaction between cues trained apart. For example, several researchers have reported attenuated responding to a target cue, $\mathrm{X}$, if a series of $\mathrm{X}-\mathrm{O}$ pairings intermixed with A-no-O trials are followed by one or more A-O trials (Lipp \& Dal Santo, in press; Lipp, Siddle, \& Dall, 1993; Ortega \& Matute, 2000; Packer \& Siddle, 1989; Siddle, 1985; Siddle, Broekhuizen, \& Packer, 1990). In these studies, the outcome is miscued during Phase 2 by the cue that predicts its absence (A). The miscuing effect can occur with just one miscuing trial, and it is more robust than retroactive interference in situations in which participants do not receive discrimination training in the target phase of treatment (i.e., the $\mathrm{X}-\mathrm{O}$ trials; see Lipp \& Dal Santo, in press, for a discussion).

A substantial body of evidence on interference between cues trained apart comes also from the classical studies on retroactive interference in the verbal learning tradition (e.g., Slamecka \& Ceraso, 1960; Underwood, 1966). Although researchers in the interference tradition more extensively studied retroactive interference with the $\mathrm{A}-\mathrm{B}, \mathrm{A}-\mathrm{C}$ paradigm (i.e., two different outcomes associated to a common cue; e.g., Bäuml, 1996, 1998; Chandler, 1993; Chandler \& Gargano, 1998), many experiments have shown that interference can also take place when two different cues are associated to a common outcome (i.e., the A-B, C-B paradigm; see, e.g., Abra, 1967; Cheung \& Goulet, 1968; Johnston, 1968; Keppel, Bonge, Strand, \& Parker, 1971; Schwartz, 1968).

The term retroactive interference is more frequently used by memory researchers and seems to have been more widely applied to conditions in which the two cues are trained elementally. Presumably, retroactive interference occurs at the time of testing (e.g., Chandler \& Gargano, 1998). In contrast, the term retrospective reval- 
uation is generally preferred by contemporary associative learning theorists and is frequently reserved for conditions in which the two cues are trained in compound. According to some theories, retrospective revaluation occurs at the time of acquisition (e.g., Larkin et al., 1998), whereas other theories assume that it occurs at the time of testing (e.g., Miller \& Matzel, 1988). Thus, the only clear difference between the effects that have been called retrospective revaluation and those called retroactive interference seems to be that the former term refers to cues trained in compound, whereas the latter refers to cues trained elementally (but see Miller \& Escobar, 2002). Because there is no reason to assume a priori that these effects imply differential underlying mechanisms, we will use the two terms interchangeably and will focus on the question of whether compound training of cues is necessary to retrospectively modify responding to a target cue without further training with that target cue (regardless of whether this impairment is the result of acquisition or retrieval processes). If compound training of cues is not a critical factor in modifying responding to the target cue, the additional question arises of whether compound training results in more robust retrospective revaluation than does elemental training, which would possibly speak to whether within-compound associations play a facilitatory role in retrospective revaluation.

In Experiment 1, a cue interaction paradigm was used in which elemental training has sometimes proven to be as effective as, or even more effective than, compound training. For example, in a study of conditioned inhibition with humans, O'Boyle and Bouton (1996) compared compound (i.e., $\mathrm{X}-\mathrm{O} 1 / \mathrm{AX}-\mathrm{O} 2$ ) versus elemental (i.e., $\mathrm{X}-\mathrm{O} 1 / \mathrm{A}-\mathrm{O} 2$ ) training of Cue $\mathrm{A}$ as a conditioned inhibitor of $\mathrm{O} 1$. Inhibition was assessed in terms of retardation in the acquisition of an A-O1 association by the compound and elemental groups. According to the predictions of associative learning theories (e.g., Rescorla \& Wagner, 1972), learning that A prevents the occurrence of $\mathrm{O} 1$ should result in a stronger A-O1 inhibitory association in the compound condition than in the elemental condition; hence, more retardation should have been observed in the compound condition. However, O'Boyle and Bouton observed similar degrees of cue interaction (inhibition) in both the elemental and the compound conditions.

Although O'Boyle and Bouton (1996) did not examine retrospective revaluation of $X$ after the Phase 2 pairings were complete, with modification their paradigm could be used to test for retrospective revaluation of the training excitor (Cue $\mathrm{X}$ ) after training of its associate (Cue A) by simply testing for the predictive status of $\mathrm{X}$ after $\mathrm{A}-\mathrm{O} 1$ pairings. Importantly, during Phase 1, all participants would presumably acquire an $\mathrm{X}-\mathrm{O} 1$ association, but only participants in the compound group would also acquire a within-compound association between $\mathrm{A}$ and $\mathrm{X}$. Thus, if within-compound associations are necessary for the occurrence of retrospective revaluation, the $\mathrm{A}-\mathrm{O} 1$ pairings should affect responding to $\mathrm{X}$ at test only in those participants who had received compound training of $X$ and $A$ during Phase 1. In Experiment 1 , we tested these predictions by using an inhibitory paradigm similar to that used by O'Boyle and Bouton but testing our participants for responding to $\mathrm{X}$ after the A-O1 pairings of Phase 2, rather than on their acquisition of the A-O1 association. In Experiment 2, elemental and compound training were compared, using an excitatory paradigm that provided convergent evidence for Experiment 1. In Experiment 2, either pairings of the target cue and the outcome (i.e., $\mathrm{X}-\mathrm{O}$ ) or the compound of these two cues and the outcome (i.e., $\mathrm{AX}-\mathrm{O}$ ) preceded pairings of the interfering cue and the outcome (i.e., A-O).

\section{EXPERIMENT 1}

In Experiment 1, four groups of participants received elemental or compound inhibitory training during Phase 1. Groups Elemental-O1 and Compound-O1 received, during Phase $1, \mathrm{X}-\mathrm{O} 1$ and $\mathrm{A}-\mathrm{O} 2$ interspersed training and $\mathrm{X}-\mathrm{O} 1$ and $\mathrm{AX}-\mathrm{O} 2$ interspersed training, respectively. During Phase 2, both groups received A-O1 pairings. The control groups, Group Elemental-O2 and Group Compound-O2, received the same treatment as Groups Elemental-O1 and Compound-O1 during Phase 1, respectively, but were presented with $\mathrm{A}-\mathrm{O} 2$ trials instead of A-O1 trials during Phase 2 (see Table 1). If interaction occurs both between individually trained cues and between compound-trained cues in this procedure, the difference in responding to $\mathrm{X}$ between Groups Elemental$\mathrm{O} 1$ and Elemental-O2 should be similar to that between Groups Compound-O1 and Compound-O2.

\section{Method}

Participants. Forty-eight undergraduate students from Deusto University volunteered for the study. The participants were randomly assigned to one of four groups $(n \mathrm{~s}=12)$.

Apparatus and Procedure. The experiment was conducted using personal computers, with the experimental contingencies being presented on the computer's monitor and participants responding through the keyboard. The computers used during the experiment were located in a room with five individual cubicles. The screen simulated an airplane's control panel, to be used in a fictitious Air Force aptitude selection test. The instructions were shown in two consecutive screens. An approximate translation from Spanish of the instructions used reads as follows:

Screen 1: You are going to take part on the Air Force's aptitude selection test. Pilots who obtain the maximum score will be accepted. Your airplane is equipped with a special control panel that will indicate

\section{Table 1}

Design of Experiment 1

\begin{tabular}{llcc}
\hline \multicolumn{1}{c}{ Group } & \multicolumn{1}{c}{ Phase 1 } & Phase 2 & Test \\
\hline Compound-O1 & X-O1/AX-O2 & A-O1 & X \\
Compound-O2 & X-O1/AX-O2 & A-O2 & X \\
Elemental-O1 & X-O1/A-O2 & A-O1 & X \\
Elemental-O2 & X-O1/A-O2 & A-O2 & X \\
\hline
\end{tabular}

Note- $\mathrm{A}$ and $\mathrm{X}$, yellow and blue lights, counterbalanced within groups; $\mathrm{O} 1$, gaining points; $\mathrm{O} 2$, losing points; /, intermixed with. 
whether or not you should shoot the airplane's guns. Your main task will be to learn how to interpret the lights in the panel. For each attack you will have a maximum of 10 shots available. Regardless of how many shots you use in a given attack, you will have 10 more shots available during the next attack. You have to decide how many shots you are going to use each time. If you shoot when you should, according to the information presented on the panel, you will gain points (the more shots you use, the more points you will win) and by contrast, if you shoot when you should not, you will lose points (the more shots you use, the more points you will lose).

Screen 2: Each shot adds or subtracts one point from your overall score. You will have to press $<$ ENTER $>$ to see the panel's information for each new attack. When the information is shown in the panel, you can indicate the number of shots you decide to use according to that information. To do this, you have to use the keyboard's cursor keys to fill the shots indicator bar presented at the right side of your screen. Once you have made your choice, press $<$ ENTER $>$ to see how many points you have won or lost.

These instructions were individually explained to each participant, using two demonstration trials with cues different from those used in the actual experiment. After this explanation was completed, the experiment began. During the experiment, the participants advanced from one trial to the next one by pressing the Enter key on the computer keyboard. No breaks were inserted between the different phases of the experiment.

The control panel had six separate lights and was located below the airplane's window, in two horizontal rows of three lights each. Cues A and X were yellow and blue lights, counterbalanced within groups. The six lights were "turned off" (represented by a black light) when no cues were presented. When one cue was presented, one light turned on, showing the color corresponding to that cue, and the other lights remained black (turned off). When a compound of two cues was presented, two lights were turned on, and the other lights remained off. The position in which the cues were presented was randomly determined for each trial.

Outcome $1(\mathrm{O} 1)$ consisted of (1) the message "You have gained: $[n]$ points" (with $[n]$ being the number of shots risked during the cue presentation) and (2) gaining one point for each shot that was risked. Outcome $2(\mathrm{O} 2)$ consisted of (1) the message "You have lost: $[n]$ points" and (2) losing one point for each shot that was risked. In each trial, the participants were given a message in the presence of the colored lights of the control panel, asking them to decide the number of shots they would like to risk on that trial (i.e.,
"Indicate the number of shots"). Presumably, the more certain the participants were that they could earn points $(\mathrm{O} 1)$, the greater number of shots they would risk in a given trial (i.e., up to 10), whereas the more certain they were that they could lose points $(\mathrm{O} 2)$, the fewer shots they would risk in a given trial (i.e., down to 0). Thus, the dependent variable assessed in the present experiment was the number of shots risked by the participants during testing.

In this experiment, the different trial types of Phase 1 were presented following a pseudorandom sequence. This sequence was $\mathrm{X}-\mathrm{O} 1, \mathrm{X}-\mathrm{O} 1, \mathrm{AX}-\mathrm{O} 2, \mathrm{X}-\mathrm{O} 1, \mathrm{AX}-\mathrm{O} 2, \mathrm{AX}-\mathrm{O} 2, \mathrm{X}-\mathrm{O} 1, \mathrm{AX}-\mathrm{O} 2$, $\mathrm{X}-\mathrm{O} 1, \mathrm{AX}-\mathrm{O} 2, \mathrm{AX}-\mathrm{O} 2, \mathrm{AX}-\mathrm{O} 2, \mathrm{X}-\mathrm{O} 1, \mathrm{AX}-\mathrm{O} 2, \mathrm{X}-\mathrm{O} 1, \mathrm{X}-\mathrm{O} 1$ for the compound groups (the elemental groups received an identical sequence, with $\mathrm{A}-\mathrm{O} 2$ trials replacing the $\mathrm{AX}-\mathrm{O} 2$ trials).

\section{Results and Discussion}

The results of this experiment are presented in Figure 1. Retrospective revaluation was observed in Group Elemental-O1, as compared with group Elemental-O2, but not in Group Compound-O1, as compared with Group Compound-O2. Moreover, there were no differences in responding to $\mathrm{X}$ between the two control groups (Groups Compound-O2 and Elemental-O2). That is, with a similar baseline for responding to $\mathrm{X}$ after compound and elemental training, retroactive revaluation of Cue $\mathrm{X}$ was greater when the cues were trained apart (elemental condition) than when they were trained together (compound condition). These conclusions were supported by the following analyses.

A 2 (type of training, elemental vs. compound) $\times 2$ (Phase 2 outcome, O1 vs. O2) analysis of variance (ANOVA) conducted on the ratings (i.e., number of shots risked) of $X$ at test revealed a main effect of Phase 2 outcome, as well as an interaction $\left[F_{\mathrm{S}}(1,44)=4.24\right.$ and 9.67, respectively, $\left.M S_{\mathrm{e}}=12.78, p \mathrm{~s}<.05\right]$. Planned comparisons using the error term from this ANOVA were conducted to analyze the source of the interaction. Responding to $\mathrm{X}$ in Group Elemental-O2 was greater than that in Group Elemental-O1 $[F(1,44)=13.36, p<.001]$. However, there

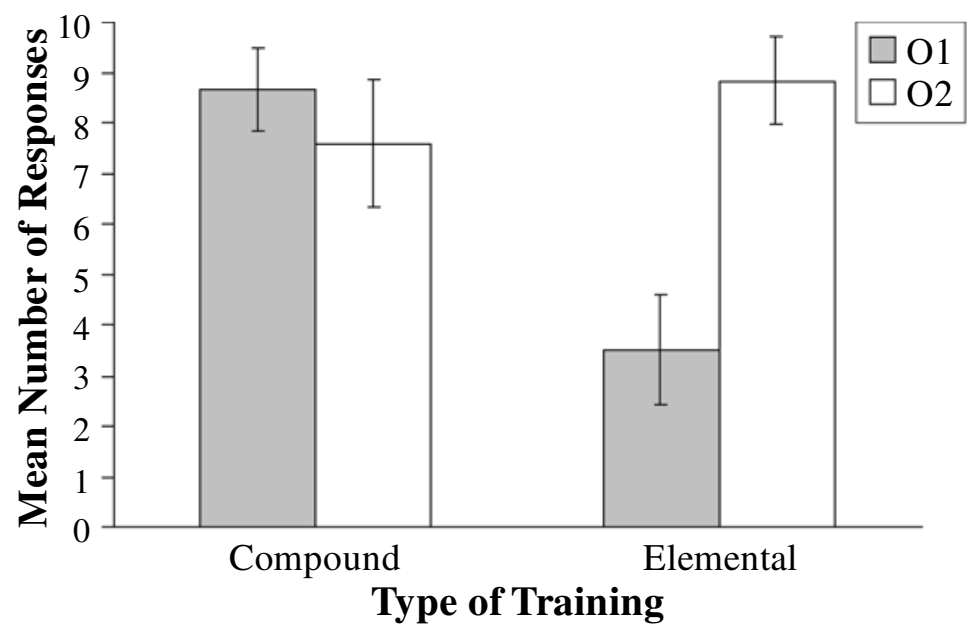

Figure 1. Mean number of responses during the test trial with $X$ in Experiment 1. Error bars represent the standard errors of the means. 
were no differences between Groups Compound-O1 and Compound-O2 $[F(1,44)<1]$. Thus, greater retrospective revaluation was observed when Cues $\mathrm{X}$ and $\mathrm{A}$ had been trained apart (elemental condition) than when these cues were trained together (compound condition).

The results of this experiment extend the findings on interaction between individually trained cues reported by Matute and Pineño (1998a, 1998b), using a different preparation and design, which speaks to the generality of these effects. Most important, these results suggest that, using the present preparation and parameters, retrospective revaluation between individually trained cues can be stronger than retrospective revaluation between compound-trained cues. These results are contrary to what could be expected on the basis of the postulates of contemporary associative learning theories (e.g., Dickinson \& Burke, 1996; Miller \& Matzel, 1988; Rescorla \& Wagner, 1972; Van Hamme \& Wasserman, 1994).

The present results do not speak to the issue of whether the source of the interference is at the moment of acquisition or at the moment of retrieval, but other reports suggest that stimulus interference is probably due to a retrieval failure that occurs when the interfering cue is more available for retrieval during testing than is the target cue. In the present case, however, it could be argued that the participants in Group Elemental-O1 learned that the contingencies changed between Phase 1 and Phase 2 . During Phase 1, they learned that X predicted O1 and A predicted $\mathrm{O} 2$; then, during Phase 2, they learned that $\mathrm{A}$ predicted $\mathrm{O} 1$, and this might have led them to expect that, symmetrically, $\mathrm{X}$ would no longer predict $\mathrm{O} 1$. Although this rule would also apply to Group Compound$\mathrm{O} 1$, in which $\mathrm{A}$ also predicted $\mathrm{O} 2$ during Phase 1 and $\mathrm{O} 1$ during Phase 2, the compound training might have somehow attenuated reversal learning. In order to assess whether reversal learning could have influenced the results of Experiment 1, we avoided pairing A (or AX) with $\mathrm{O} 2$ during Phase 1 in Experiment 2.

It should be noted, however, that Groups Elemental-O1 and Compound-O1 were modeled directly from the studies in which inhibition with compound trials (commonly known as Pavlov's procedure) was compared with inhibition in situations that did not require compound trials (in this case, the so-called differential procedure). To the best of our knowledge, reversal learning has not been an issue in those studies. Indeed, our results are consistent with several other studies in which a similar design was used that have also observed reliable cue interaction effects in the elemental (i.e., differential) inhibition condition (see, e.g., O'Boyle \& Bouton, 1996, and Williams, Travis, \& Overmier, 1986, for reviews). Moreover, these results are also consistent with many other studies that have found no evidence of interference (retrospective revaluation) after compound training (e.g., Shanks, Darby, \& Charles, 1998; Wilson \& Pearce, 1992). Most of those studies have attributed the resistance to interference that often occurs in the compound conditions to compound training favoring configural processing, unless special procedures are used to favor elemental processing (see also Williams, Sagness, \&
McPhee, 1994). For this reason, in Experiment 2, elemental training was defined as training in which the target and the potentially interfering cue were not presented in compound. However, in the elemental condition, the target cues were presented in compound with cues irrelevant to the revaluation treatment, so that configural processing would equally affect the two conditions and similar degrees of cue interaction could be observed between them.

\section{EXPERIMENT 2}

The main purpose of Experiment 2 was to extend the results of Experiment 1, using an excitatory paradigm. In addition, for the reasons stated above, configural processing was made equally likely in the elemental and the compound conditions, so that equivalent degrees of retrospective revaluation could be observed in both cases. For this purpose, the target cue, $\mathrm{X}$, was trained in compound in all groups during Phase 1, but the competing cue trained during Phase 2 was either the Phase 1 companion cue (Condition Together) or a different cue (Condition Apart). Thus, Experiment 2 compared interaction between cues trained together (analogous to the compound condition in Experiment 1) and interaction between cues trained apart (analogous to the elemental condition in Experiment 1) in an excitatory preparation (see Table 2).

In addition, in this experiment, we chose to use a preparation that had proven successful in obtaining retrospective revaluation with individually trained cues (Pineño et al., 2000) but that was different from that used in Experiment 1 and in Matute and Pineño's (1998b) studies (for a full description of the task used by Matute \& Pineño, 1998b, see Arcediano, Ortega, \& Matute, 1996). Introducing yet one more experimental preparation is not without its problems, in that it reduces comparability among different experiments. However, our reason for doing so was twofold. First, using a different preparation is necessary when one wants to assess the generality of the results. Second, recent studies conducted in our laboratory have provided results indicating that the preparation developed by Pineño et al. is more sensitive to (compound and elemental) cue interaction effects than are the tasks used in Experiment 1 and by Matute and Pineño (1998b). ${ }^{1}$

\section{Method}

Participants. Eighty undergraduate students from Deusto University volunteered for the study. The participants were randomly assigned to one of four groups $(n \mathrm{~s}=20)$.

Table 2

Design of Experiment 2

\begin{tabular}{lllc}
\hline \multicolumn{1}{c}{ Group } & \multicolumn{1}{c}{ Phase 1 } & Phase 2 & Test \\
\hline Together-O1 & AX-O1/C-O2 & A-O1 & X \\
Together-no-O & AX-O1/C-O2 & A-no-O & X \\
Apart-O1 & BX-O1/C-O2 & A-O1 & X \\
Apart-no-O & BX-O1/C-O2 & A-no-O & X \\
\hline
\end{tabular}

Note-A, B, and X, blue, red, and green lights, counterbalanced within groups; $\mathrm{C}$, yellow light; $\mathrm{O} 1$, gaining points; $\mathrm{O} 2$, losing points; no-O, no outcome; /, intermixed with. $\mathrm{C}-\mathrm{O} 2$ trials were inserted so that the participants would not tend to respond indiscriminately to any stimulus that appeared on the screen. 
Apparatus and Procedure. The apparatus was the same as that described in Experiment 1, with the exception of the task. In Experiment 2 , the participants were asked to imagine that they were to rescue a group of refugees by helping them escape from a war zone in several trucks (see Pineño et al., 2000). A translation of the instructions from Spanish reads as follows.

Screen 1: Imagine that you are a soldier for the United Nations. Your mission consists of rescuing a group of refugees that are hidden in a ramshackle building. The enemy has detected them and has sent forces to destroy the building .... But, fortunately, they rely on your cunning to escape the danger zone before that happens.

You have several trucks for rescuing the refugees, and you have to help them get into those trucks. There are two ways of placing people in the trucks:

Pressing the space bar repeatedly, so that one person per press is placed in a truck.

Maintaining the space bar pressed down, so that you will be able to load people very rapidly.

If you rescue a number of persons in a given trip, they will arrive to their destination alive, and you will be rewarded with a point for each person. You must gain as many points as possible!

Screen 2: But ... your mission will not be as simple as it seems. The enemy knows of your movements and could have placed deadly mines on the road. If the truck hits a mine, it will explode, and the passengers will die. Each dead passenger will count as one negative point for you. Fortunately, the colored lights on the SPY-RADIO will tell you about the state of the road. These lights can indicate that:

(a) The road will be free of mines. $\rightarrow$ The occupants of the truck will be liberated. $\rightarrow$ You will gain points.

(b) The road will be mined. $\rightarrow$ The occupants of the truck will die. $\rightarrow$ You will lose points.

(c) There are no mines, but the road is closed. $\rightarrow$ The occupants of the truck will neither die nor be liberated. $\rightarrow$ You will neither gain nor lose points: You will maintain your previous score.

Screen 3: At first, you will not know what each color light of the SPYRADIO means. However, as you gain experience with them, you will learn to interpret what they mean.

Thus, we recommend that you:

(a) Place more people in the truck the more certain you are that the road will be free of mines (keep the space bar continuously pressed down ONLY if you are completely sure that there are no mines, because in this way you will put a lot of people in the truck ... .)

(b) Introduce less people in the truck the more certain you are that the road is mined.

After these instructions, the participants were shown a fourth screen that gave instructions about contextual changes. Although contextual changes were not used in the present experiment, in order to avoid making more changes than necessary between different experimental series conducted with the same preparation, we maintained a fourth instruction screen in the program for the task. A translation of the fourth instruction screen reads as follows.

Screen 4: Finally, it is important to know that your mission may take place in several different towns. The colors on the SPY-RADIO can mean the same or a very different thing depending on the town in which you are. Thus, it is important to pay attention to the message that indicates the place in which you are. If you travel to another town, the message indicating the name of the town will change. When a change of destination is occurring, you will read the message "Traveling to another town," so you will be continuously informed about such changes. Nevertheless, sometimes you might end up returning to the same town even if you have seen the message that indicates that you are traveling. Do not worry if all this looks very complex at this point. Before we start, you will have the opportunity to see the location of everything (radio, town name, messages, scores, etc.) on the screen, and to ask the experimenter about anything that is unclear.

The cues were presented in the "spy-radio," which consisted of six panels in which colored lights could be presented. Cues X, A, and $\mathrm{B}$ were blue, red, and green lights, counterbalanced. Cue $\mathrm{C}$ was a yellow light. All the cues were presented for $3 \mathrm{sec}$. During the intertrial intervals (ITIs), the lights were turned off (i.e., gray). The mean ITI duration was $5 \mathrm{sec}$, ranging between 3 and $7 \mathrm{sec}$. During each cue presentation, each response (i.e., pressing the space bar once) placed 1 refugee in the truck, whereas holding the space bar down placed up to 30 refugees per second in the truck. The termination of the cue always coincided with the onset of the outcome.

Outcome $1(\mathrm{O} 1)$ consisted of (1) the message " $[n]$ refugees safe at home!!!" (with $[n]$ being the number of refugees introduced in the truck during the cue presentation) and (2) gaining one point for each refugee who was liberated. Outcome $2(\mathrm{O} 2)$ consisted of (1) the message " $[n]$ refugees have died!!!" and (2) losing one point for each refugee who died in the truck. No-outcome (no-O) consisted of (1) the message "Road closed" and (2) maintaining the previous score. Outcome messages were presented for $3 \mathrm{sec}$. The number of refugees that the participants risked taking in each truck was our dependent variable. Presumably, the more certain they were that the trip would be successful $(\mathrm{O} 1)$, the greater the number of refugees they would take, whereas the more certain they were that the truck would explode $(\mathrm{O} 2)$, the fewer refugees they would risk placing in the truck.

A score panel on the screen provided information about the number of refugees the participant was introducing into the truck on each trial. Although pressing the space bar during the outcome message had no consequences, this panel remained visible during the presentation of the outcome and showed the number of people that had boarded the truck while the cue was present. Upon outcome termination, the score panel was initialized to 0 . Responses that occurred during the ITIs had no consequence and were not reflected in the panel.

During Phase 1, the participants were exposed to 4 pairings of the AX or BX compounds with O1 (Conditions Together and Apart, respectively), intermixed with four $\mathrm{C}-\mathrm{O} 2$ trials. These $\mathrm{C}-\mathrm{O} 2$ trials were used to prevent generalization of responding to cues other than the cues paired with the outcome. The pseudorandom sequence of Phase 1 trials generated for this experiment was $\mathrm{AX}-\mathrm{O} 1, \mathrm{AX}-\mathrm{O} 1$, $\mathrm{C}-\mathrm{O} 2$, AX-O1, C-O2, C-O2, AX-O1, C-O2, for Condition Together. An identical sequence was generated for Condition Apart, except that $\mathrm{BX}-\mathrm{O} 1$ replaced the $\mathrm{AX}-\mathrm{O} 1$ trials. In Phase 2, the participants in the $\mathrm{O} 1$ condition received $16 \mathrm{~A}-\mathrm{O} 1$ pairings, whereas the participants in the no-O condition received $16 \mathrm{~A}-$-no-O pairings. All the participants then received one test trial with $\mathrm{X}$.

\section{Results and Discussion}

Figure 2 presents the results of this experiment. Retrospective revaluation was observed in both Conditions Apart and Together. That is, responding to the target cue, $\mathrm{X}$, was weaker in Group Apart-O1 than in Group Apart-no-O and was also weaker in Group Together-O1 than in Group Together-no-O. Thus, with the present design and parameters, we observed retrospective revaluation both between cues trained together and between cues trained apart. The following analyses support our conclusions.

A 2 (type of training, together vs. apart) $\times 2$ (Phase 2 outcome, $\mathrm{O} 1$ vs. no-O) ANOVA conducted on responding to $X$ at test revealed a main effect of Phase 2 outcome $\left[F(1,76)=10.34, M S_{\mathrm{e}}=633.47, p<.005\right]$ but no effect of type of training and no interaction $(p s>.27)$. Pairwise comparisons revealed that responding to $\mathrm{X}$ in Group Apart$\mathrm{O} 1$ was weaker than in Group Apart-no-O $[F(1,76)=$ $4.32, p<.05$ ] and responding to $\mathrm{X}$ in Group Together-O1 was weaker than that in Group Together-no-O $[F(1,76)=$ 


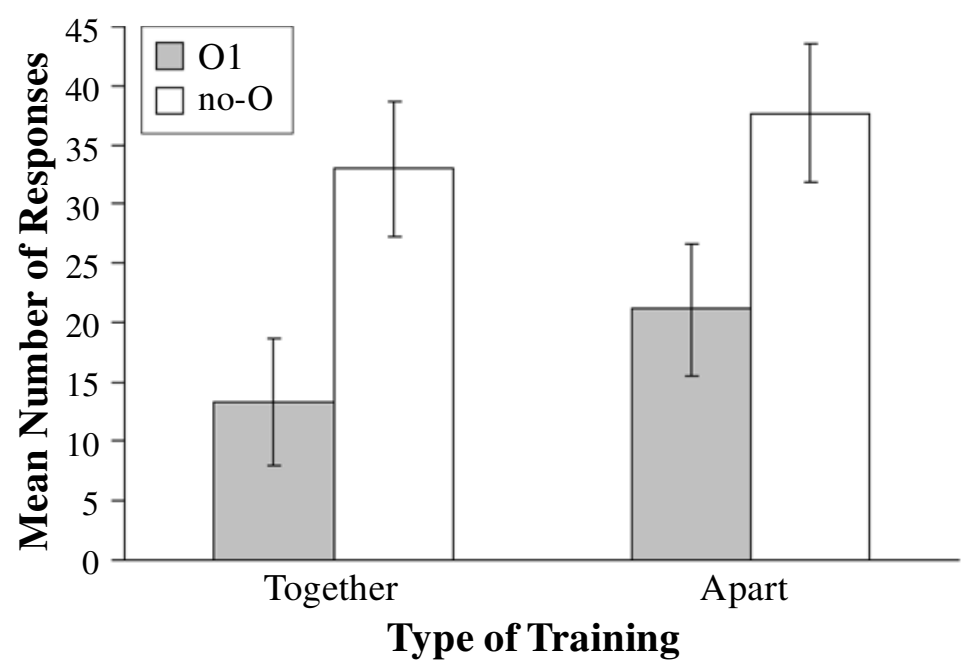

Figure 2. Mean number of responses during the test trial with $X$ in Experiment 2. Error bars represent the standard errors of the means.

$6.10, p<.05]$. That is, the present design and parameters resulted in similar degrees of cue interaction occurring between cues trained apart and between cues trained together.

\section{GENERAL DISCUSSION}

In two experiments, we compared the strength of retrospective revaluation obtained between cues that had been presented together at some point during training with that obtained between cues that were always presented apart. In Experiment 1, we compared elemental versus compound inhibitory training and observed retrospective revaluation between cues trained apart, but not between cues trained in compound (for similar results in inhibitory cue interaction, see O'Boyle \& Bouton, 1996; Williams et al., 1986). In Experiment 2, we used an excitatory paradigm in which the target cue was always presented in compound with another cue, either the interfering cue trained during Phase 2 (Condition Together, which was essentially backward blocking) or a different cue irrelevant to the revaluation treatment (Condition Apart). With this manipulation, we observed retrospective revaluation both between cues trained apart and between cues trained in compound, and the sizes of these revaluation effects were similar. Thus, these results support previous reports that compound training is not necessary for retrospective revaluation to occur. More important, these two experiments, taken together, suggest that contrary to the predictions of most contemporary associative learning theories, compound training can sometimes hamper, rather than favor, the occurrence of retrospective revaluation (see also Williams et al., 1994).

Although our finding of retrospective revaluation (or retroactive interference) with elementally trained cues might seem surprising from the point of view of current associative learning theories, it should be noted that our findings are not as novel as they might seem. As was noted in the introduction, additional examples of interference between elementally trained cues can be found in what was usually called the $\mathrm{A}-\mathrm{B}, \mathrm{C}-\mathrm{B}$ paradigm in the verbal learning literature (e.g., Abra, 1967; Cheung \& Goulet, 1968; Johnston, 1968; Keppel et al., 1971; Schwartz, 1968). Those studies on paired-associates learning have generally been overlooked by current theories of associative learning, perhaps because those studies were generally more concerned with retrieval of memory than with the predictive value of the cues. However, the present experiments are basically $\mathrm{A}-\mathrm{B}, \mathrm{C}-\mathrm{B}$ paradigms in which $\mathrm{A}$ and $\mathrm{C}$ are different cues (colored lights) that predict a common outcome, B (gaining points). The finding that interference can also occur in predictive learning, regardless of whether or not within-compound associations are established, suggests the possibility of integrating the literature on elemental cues (called retroactive interference in the paired associate tradition) with the studies on compound cues (called retrospective revaluation in the associative learning tradition).

Our results are also consistent with recent reports of interaction between elementally trained cues (e.g., Escobar, Arcediano, \& Miller, 2001; Escobar, Matute, \& Miller, 2001; Matute \& Pineño, 1998a, 1998b; Ortega \& Matute, 2000; Pineño et al., 2000; Pineño \& Matute, 2000), as well as with several reports that show interaction between cues that have received differential (i.e., elemental) inhibition training (e.g., Lipp et al., 1993; Packer \& Siddle, 1989; Siddle, 1985; Siddle et al., 1990). Moreover, some of the comparisons of the elemental and compound inhibition procedures that have been reported in the literature are also consistent with the results of Experiment 1. In an animal study, Williams et al. (1986) observed more robust inhibition with the el- 
emental (differential) procedure than with the compound (Pavlov's) procedure. Similarly, O'Boyle and Bouton (1996, Experiment 1) reported similar levels of inhibition in a compound (Pavlov's) procedure and in an elemental (differential) procedure, using a predictive task with human participants. Moreover, in their Experiment 2, O'Boyle and Bouton observed that inhibition obtained with the elemental procedure was greater than that obtained with the compound procedure. The resistance to interference in the compound condition has been generally attributed to compound presentation of cues favoring configural, rather than elemental, processing strategies (see Shanks et al., 1998; Williams et al., 1994; Wilson \& Pearce, 1992).

Our using different experimental tasks for the two experiments deserves some comment. On the one hand, comparisons between different experiments in the same research area should benefit from the use of similar preparations. On the other hand, it is also true that using different preparations is necessary when one wants to test the generality of the effects and to ensure that they are not artifacts produced by the details of particular preparations. In further support of the idea that interaction between cues trained apart is a general phenomenon of associative learning, Escobar, Matute, and Miller (2001; see also Escobar, Arcediano, \& Miller, 2001) reported analogous evidence of interference, using rats as subjects in a conditioned lick suppression preparation. The observation of similar effects of interaction between elementally trained cues in different species (rats and humans), with different tasks (various computer preparations and paired-associates learning), using different cues (different audiovisual stimuli), and with different parameters (the present experiments and the miscuing effect) suggests that these are not isolated results.

Our finding retrospective revaluation irrespective of whether $\mathrm{X}$ was trained in compound with A or with a different cue can be interpreted as contrary to Dickinson and Burke's (1996; see also Aitken et al., 2001) suggestion that retrospective revaluation takes place only if there is a strong within-compound association between the target and the interfering cues. It should be noted, however, that there are too many differences between their procedure and ours that could be responsible for our observation of retrospective revaluation in both conditions. Although careful parametric manipulations should be performed to illuminate the basis of this difference, below we discuss some of the factors that might influence the occurrence of retrospective revaluation in the absence of strong within-compound associations.

A possible source for this discrepancy (i.e., the assumption that retrospective revaluation requires strong within-compound association vs. reports of retrospective revaluation in the absence of compound training) is the differential sensitivity of experimental tasks to detect interaction between cues trained apart. Among the several tasks we have used in our laboratory to obtain interactions between individually trained cues, the task used in Experiment 2 has proven to be the most sensitive, whereas the task used by Dickinson and colleagues (Aitken et al., 2001; Dickinson \& Burke, 1996) has proven to be the least sensitive. Dickinson and colleagues used a causal judgment task in which participants were requested to give their subjective rating of the degree to which they believed that the cue (i.e., a particular food) was the cause of the outcome (i.e., an allergic reaction). Despite our failure to obtain interference in causal judgment tasks (see Matute \& Pineño, 1998a, for a review), some reports in the literature have suggested that interaction between elementally trained cues could be observed even in causal judgments tasks if the right parameters were used. Wasserman and Berglan (1998) reported a study in which participants received $\mathrm{AW}-\mathrm{O} 1$, $\mathrm{BX}-\mathrm{O} 1$, and $\mathrm{CY}-\mathrm{O} 1$ trials in Phase 1 , followed by A-O1 and C-no-O trials in Phase 2. Then, W, X, and Y were presented at test. Wasserman and Berglan expected that, as compared with the ratings at the end of Phase 1, the training of Phase 2 would produce a decrease in the ratings of $\mathrm{W}$ (i.e., backward blocking, because of the within-compound association between $\mathrm{A}$ and $\mathrm{W}$ ), an increase in the ratings of $Y$ (i.e., recovery from overshadowing, because of the within-compound association between $\mathrm{C}$ and $\mathrm{Y}$ ), and no change in the ratings of $\mathrm{X}$ (i.e., because its companion cue, $\mathrm{B}$, was not presented during Phase 2). That is, they expected responding at test to be $\mathrm{W}<\mathrm{X}<\mathrm{Y}$. However, although the $\mathrm{X}<\mathrm{Y}$ difference was confirmed, the difference between $\mathrm{X}$ and $\mathrm{W}$ did not reach statistical significance, because the rating for both cues decreased after the Phase 2 training, relative to the ratings at the end of Phase 1. As Wasserman and Berglan noted, this decrease in the ratings of $X$ could be viewed as reflecting some degree of interaction between cues not trained in compound. They reported that a difference between $\mathrm{X}$ and $\mathrm{W}$ was observed in their study only when the data from participants who, on a postexperimental test, were not able to recall which cues had been presented together were eliminated from the analysis. Similar results have been reported by Dickinson and his colleagues (e.g., Larkin et al., 1998, Experiments 1 and 2). They used a within-subjects design analogous to that used by Wasserman and Berglan and also observed the $\mathrm{X}<\mathrm{Y}$ effect, but not the $\mathrm{W}<\mathrm{X}$ effect. According to Larkin et al., the $\mathrm{W}<\mathrm{X}$ effect is parameter dependent. Although speculative, the results of Experiment 1 seem to support this assumption, since retroactive interference was not observed in the compound condition with the specific parameters used.

Although the purpose of the present paper was not to explore the mechanisms that might produce retrospective revaluation between cues trained together and between cues trained apart, the results of these experiments, together with other data on cue competition and interference, suggest that the two effects can be explained by a common mechanism. Retrospective revaluation between both elementally trained and compoundtrained cues can be explained by Dickinson and Burke's 
(1996) revised SOP model if it is assumed that the absent cue, $\mathrm{X}$, can become associatively activated not only by cues that have a within-compound association with X, but also by the outcome itself (see Escobar, Matute, \& Miller, 2001; Matute and Pineño, 1998a). According to this view, $\mathrm{X}$ and $\mathrm{O} 1$ would form inhibitory associations during Phase 2 because $X$ is absent during trials in which the outcome is present. This approach can also account for retrospective revaluation between cues trained apart being sometimes stronger than retrospective revaluation between cues trained in compound (Experiment 1). Potentially, the compound ( $\mathrm{AX}-$ no-O/X-O1) training results in the formation of a weaker $\mathrm{X}-\mathrm{O} 1$ association than the elemental (A-no-O/X-O1) training because, in the former case, the A-X association could potentially overshadow the $\mathrm{X}-\mathrm{O} 1$ association. Consequently, the presentation of $\mathrm{O} 1$ during Phase 2 would better activate the representation of $\mathrm{X}$ in the elemental than in the compound groups, thus yielding a stronger $\mathrm{X}-\mathrm{O} 1$ inhibitory association (i.e., stronger retrospective revaluation of $\mathrm{X})$. By the same reasoning, elemental interference should not be stronger than compound interference if the elemental cue is trained in compound with an irrelevant cue, as was the case in our Experiment 2 (Condition Apart).

A problem with this approach is that it also predicts that O1-alone presentations during Phase 2 should produce retrospective revaluation of the $\mathrm{X}-\mathrm{O} 1$ association. However, several studies have reported no effect of the $\mathrm{O} 1$-alone presentations in situations in which the number of these $\mathrm{O} 1$-alone trials is maintained low enough to prevent a degradation of the $\mathrm{X}-\mathrm{O} 1$ contingency (e.g., Escobar, Arcediano, \& Miller, 2001; Escobar, Matute, \& Miller, 2001, Experiments 2-4; Ortega \& Matute, 2000, Experiment 2). Quite possibly, this is due to the formation of a context-O1 association that could produce some responding during testing to $\mathrm{X}$. This responding, produced by the contextual cues, could summate to the response produced by $\mathrm{X}$, thereby producing a final stronger response. ${ }^{2}$ Thus, in order to adequately assess the possibility of retrospective revaluation caused by $\mathrm{O} 1$ alone trials, testing on $\mathrm{X}$ should be performed in a different (physical or temporal) context from that in which $\mathrm{O} 1$ was presented alone. However, it is not easy to test this view, because contextual switches would produce collateral effects here: Many experiments have shown that contextual changes produce renewal of responding to $\mathrm{X}$ following interference (e.g., Escobar, Matute, \& Miller, 2001, Experiment 3; Matute \& Pineño, 1998b, Experiment 3; Pineño \& Matute, 2000, Experiment 1). Moreover, Dickinson and Burke's (1996) revised SOP model cannot explain recovery of responding following retrospective revaluation between elementally trained cues owing to contextual manipulations (Matute and Pineño, 1998b, Experiment 3), the introduction of a retention interval (Pineño et al., 2000, Experiment 1), or the presentation of retrieval cues (Pineño et al., 2000, Experiment 3; see Escobar, Matute, \& Miller, 2001, for similar manipulations in nonhuman subjects). These studies suggest that for interference to take place, it is also necessary that an interfering association be more strongly primed at the time of testing than the target association.

Thus, a potential way to incorporate most of the interference results within the SOP framework would imply the application of a mechanism by which excitatory and inhibitory associations could be selectively retrieved depending on the different contextual and temporal manipulations performed at testing. According to Matute and Pineño (1998a), this could be achieved by integrating within the SOP framework the assumptions of Bouton's (1993) retrieval theory of interference between outcomes. According to Bouton's theory, excitatory associations easily transfer to novel (physical and/or temporal) contexts, but retrieval of inhibitory associations is modulated by the presence of (physical and/or temporal) contextual cues that became associated with the memory of inhibition during inhibitory training. Although Bouton developed his theory to account for interference between outcomes (e.g., extinction and counterconditioning), his assumptions on the contextual specificity of the inhibitory associations could be extended in order to account for interference between cues. The present results add further support to the idea that the integration of Bouton's model with Dickinson and Burke's (1996) revision of Wagner's (1981) SOP model can account for most instances of retrospective revaluation and retroactive interference, both between cues and between outcomes.

Alternatively, Miller and Escobar (2002) have recently proposed a dual-mechanism approach to account for both cue competition and interference effects. According to this approach, two mechanisms would be simultaneously at work in all situations. The first is a comparator mechanism (cf. Miller \& Matzel, 1988), according to which responding to a target cue is directly related to the degree to which the target directly activates a representation of the outcome and inversely related to the degree to which the target indirectly activates a representation of the outcome through other cues that have become associated to the target during training (so-called comparator cues). The second mechanism is a priming mechanism, according to which responding to the target would be directly related to the degree to which the context of testing primes the target association and inversely related to the degree to which the context of testing primes other associations. Activation of the comparator mechanism requires a within-compound association between the target and the interfering cues; activation of the priming mechanism requires that the target and the interfering cues have different priming stimuli. According to Miller and Escobar, when the target and the interfering cues are trained in compound, the comparator mechanism will be maximally active (there is a within-compound association between the cues), and the priming mechanism will be minimally active (both 
the target and the interfering cue would have the same priming stimuli). In contrast, when the target and the interfering cues are trained apart, the comparator mechanism will be minimally active (there is no within-compound association between the cues), and the priming mechanism will be maximally active (the target and the interfering cue each have their own, distinct priming stimuli).

At this point, we are not prepared to favor one interpretation above the other. However, we strongly believe that integrative strategies, such as those reviewed here, can explain both compound and elemental interference and benefit from a common theoretical framework that should prove more fruitful than the existing compartmentalization of data from the two separate research designs.

\section{REFERENCES}

AвrA, J. C. (1967). Time changes in the strength of forward and backward associations. Journal of Verbal Learning \& Verbal Behavior, 6 , 640-645.

Aitken, M. R. F., Larkin, M. J. W., \& Dickinson, A. (2001). Reexamination of the role of within-compound associations in the retrospective revaluation of causal judgments. Quarterly Journal of Experimental Psychology, 54B, 27-51.

Arcediano, F., Ortega, N., \& Matute, H. (1996). A behavioural preparation for the study of human Pavlovian conditioning. Quarterly Journal of Experimental Psychology, 49B, 270-283.

BäUmL, K.-H. (1996). Revisiting an old issue: Retroactive interference as a function of the degree of original and interpolated learning. Psychonomic Bulletin \& Review, 3, 380-384.

BäUmL, K.-H. (1998). Strong items get suppressed, weak items do not: The role of item strength in output interference. Psychonomic Bulletin \& Review, 5, 459-463.

Bouton, M. E. (1993). Context, time, and memory retrieval in the interference paradigms of Pavlovian learning. Psychological Bulletin, 114, 80-99.

Chandler, C. C. (1993). Accessing related events increases retroactive interference in a matching recognition test. Journal of Experimental Psychology: Learning, Memory, \& Cognition, 19, 967-974.

Chandler, C. C., \& Gargano, G. J. (1998). Retrieval processes that produce interference in modified forced-choice recognition tests. Memory \& Cognition, 26, 220-231.

Chapman, G. B. (1991). Trial order affects cue interaction in contingency judgment. Journal of Experimental Psychology: Learning, Memory, \& Cognition, 17, 837-854.

Cheung, C. G., \& Goulet, L. R. (1968). Retroactive inhibition of R-S associations in the A-B, B-C, C-B paradigms. Journal of Experimental Psychology, 76, 327-328.

Denniston, J. C., Miller, R. R. \& Matute, H. (1996). Biological significance as a determinant of cue competition. Psychological Science, 7, 325-331.

Dickinson, A., \& Burke, J. (1996). Within-compound associations mediate the retrospective revaluation of causality judgments. Quarterly Journal of Experimental Psychology, 49B, 60-80.

Escobar, M., Arcediano, F., \& Miller, R. R. (2001). Conditions favoring retroactive interference between antecedent events (cue competition) and between subsequent events (outcome competition). Psychonomic Bulletin \& Review, 8, 691-697.

Escobar, M., Matute, H., \& Miller, R. R. (2001). Cues trained apart compete for behavioral control in rats: Convergence with the associative interference literature. Journal of Experimental Psychology: General, 130, 97-115.

Johnston, W. A. (1968). Bidirectional interference in an A-B, C-B paradigm. Journal of Verbal Learning \& Verbal Behavior, 7, 305-311.

KAMIN, L. J. (1968). "Attention-like" processes in classical conditioning. In M. R. Jones (Ed.), Miami symposium on the prediction of behavior: Aversive stimulation (pp. 9-31). Miami: University of Miami Press.
Kaufman, M. A., \& Bolles, R. C. (1981). A nonassociative aspect of overshadowing. Bulletin of the Psychonomic Society, 18, 318-320.

Keppel, G., Bonge, D., Strand, B. Z, \& Parker, J. (1971). Direct and indirect interference in the recall of paired associates. Journal of Experimental Psychology, 88, 414-422.

Larkin, M. J. W., Aitken, M. R. F., \& Dickinson, A. (1998). Retrospective revaluation of causal judgments under positive and negative contingencies. Journal of Experimental Psychology: Learning, Memory, \& Cognition, 24, 1331-1352.

LipP, O. V., \& Dal Santo, L. A. (in press). Cue competition between elementary trained stimuli: US miscuing, interference, and US omission. Learning \& Motivation.

LipP, O. V., SidDle, D. A. T., \& DAll, P. J. (1993). Effects of miscuing on Pavlovian conditioned responding and on probe reaction time. Australian Journal of Psychology, 45, 161-167.

Matute, H., Arcediano, F., \& Miller, R. R. (1996). Test question modulates cue competition between causes and between effects. Journal of Experimental Psychology: Learning, Memory, \& Cognition, 22, 182-196.

Matute, H., \& Pineño, O. (1998a). Cue competition in the absence of compound training: Its relation to paradigms of interference between outcomes. In D. L. Medin (Ed.), The psychology of learning and motivation (Vol. 38, pp. 45-81). San Diego: Academic Press.

Matute, H., \& Pineño, O. (1998b). Stimulus competition in the absence of compound conditioning. Animal Learning \& Behavior, 26, 3-14.

Matzel, L. D., Schachtman, T. R. \& Miller, R. R. (1985). Recovery of an overshadowed association achieved by extinction of the overshadowing stimulus. Learning \& Motivation, 16, 398-412.

Miller, R. R., \& Escobar, M. (2002). Associative interference between cues and between outcomes presented together and presented apart: An integration. Behavioural Processes, 57, 163-185.

Miller, R. R., \& Matute, H. (1996). Biological significance in forward and backward blocking: Resolution of a discrepancy between animal conditioning and human causal judgment. Journal of Experimental Psychology: General, 125, 370-386.

Miller, R. R., \& MAtzel, L. D. (1988). The comparator hypothesis: A response rule for the expression of associations. In G. H. Bower (Ed.), The psychology of learning and motivation (Vol. 22, pp. 5192). San Diego: Academic Press.

O'Boyle, E. A., \& Bouton, M. E. (1996). Conditioned inhibition in a multiple-category learning task. Quarterly Journal of Experimental Psychology, 49B, 1-23.

Ortega, N., \& MATUte, H. (2000). Interference between elementally trained stimuli can take place in one trial. Learning \& Motivation, 31, 323-344.

PAcker, J. S., \& Siddle, D. A. T. (1989). Stimulus miscuing, electrodermal activity, and the allocation of processing resources. Psychophysiology, 26, 192-200.

Pavlov, I. P. (1927). Conditioned reflexes (G. V. Anrep, Trans.). London: Oxford University Press.

Pineño, O., \& Matute, H. (2000). Interference in human predictive learning when associations share a common element. International Journal of Comparative Psychology, 13, 16-33.

Pineño, O., Ortega, N., \& Matute, H. (2000). The relative activation of the associations modulates interference between elementallytrained cues. Learning \& Motivation, 31, 128-152.

Rescorla, R. A., \& Wagner, A. R. (1972). A theory of Pavlovian conditioning: Variations in the effectiveness of reinforcement and nonreinforcement. In A. H. Black \& W. F. Prokasy (Eds.), Classical conditioning II: Current research and theory (pp. 64-99). New York: Appleton-Century-Crofts.

Schwartz, M. (1968). Effect of stimulus class on transfer and RI in the A-B, A-C paradigm. Journal of Verbal Learning \& Verbal Behavior, 7, 189-195.

SHANKS, D. R. (1985). Forward and backward blocking in human contingency judgment. Quarterly Journal of Experimental Psychology, 37B, 1-21.

Shanks, D. R, Darby, R. J., \& Charles, D. (1998). Resistance to interference in human associative learning: Evidence of configural pro- 
cessing. Journal of Experimental Psychology: Animal Behavior Processes, 24, 136-150.

Shanks, D. R., López, F. J., Darby, R. J., \& Dickinson, A. (1996). Distinguishing associative and probabilistic contrast theories of human contingency judgment. In D. R. Shanks, K. J. Holyoak, \& D. L. Medin (Eds.), The psychology of learning and motivation: Vol. 34. Causal learning (pp. 265-311). San Diego: Academic Press.

SidDle, D. A. T. (1985). Effects of stimulus omission and stimulus change on dishabituation of the skin conductance response. Journal of Experimental Psychology: Learning, Memory, \& Cognition, 11, 206-216.

Siddle, D. A. T., Broekhuizen, D., \& Packer, J. S. (1990). Stimulus miscuing and dishabituation: Electrodermal activity and resources allocation. Biological Psychology, 31, 229-243.

Slamecka, N. J., \& Ceraso, J. (1960). Retroactive and proactive inhibition of verbal learning. Psychological Bulletin, 57, 449-475.

Underwood, B. J. (1966). Experimental psychology (2nd ed.). New York: Appleton-Century-Crofts.

Van Hamme, L. J., \& Wasserman, E. A. (1994). Cue competition in causality judgments: The role of nonpresentation of compound stimulus elements. Learning \& Motivation, 25, 127-151.

WAGNER, A. R. (1981). SOP: A model of automatic memory processing in animal behavior. In N. E. Spear \& R. R. Miller (Eds.), Information processing in animals: Memory mechanisms (pp. 5-47). Hillsdale, NJ: Erlbaum.

Wagner, A. R, Logan, F. A., Haberlandt, K., \& Price, T. (1968). Stimulus selection and a "modified continuity theory." Journal of Experimental Psychology, 76, 171-180.

WASSERman, E. A., \& Berglan, L. R. (1998). Backward blocking and recovery from overshadowing in human causal judgment: The role of within-compound associations. Quarterly Journal of Experimental Psychology, 51B, 121-138.
Wasserman, E. A., KaO, S.-F., Van Hamme, L. J., Katagari, M., \& Young, M. E. (1996). Causation and association. In D. R. Shanks, K. J. Holyoak, \& D. L. Medin (Eds.), The psychology of learning and motivation: Vol. 34. Causal learning (pp. 207-264). San Diego: Academic Press.

Williams, D. A., Sagness, K. E., \& McPhee, J. E. (1994). Configural and elemental strategies in predictive learning. Journal of Experimental Psychology: Learning, Memory, \& Cognition, 20, 694-709.

Williams, D. A., Travis, G. M., \& Overmier, J. B. (1986). Withincompound associations modulate the relative effectiveness of differential and Pavlovian conditioned inhibition procedures. Journal of Experimental Psychology: Animal Behavior Processes, 12, 351-362.

Wilson, P. N., \& Pearce, J. M. (1992). A configural analysis of feature-negative discrimination learning. Journal of Experimental Psychology: Animal Behavior Processes, 18, 265-272.

\section{NOTES}

1. A demonstration version of the computer programs we are using can be downloaded from http://sirio.deusto.es/matute/software.html.

2. Most nonhuman preparations require restabilization sessions prior to testing, which are intended to extinguish the excitatory potential of the context and return the animals to a baseline with which uncontaminated conditioned responding to the test cue can be assessed. However, even after this treatment, there is still a subthreshold contextual excitatory response potential, which could summate with the excitatory response potential of the test cue.

(Manuscript received November 26, 2001; revision accepted for publication April 14, 2002.) 